\title{
A comparative meta-analysis of the prevalence of exercise addiction in adults with and without indicated eating disorders
}

Mike Trott ${ }^{1}$; Sarah E. Jackson ${ }^{2}$; Joseph Firth ${ }^{3,4,5}$; Louis Jacob ${ }^{6}$; Igor Grabovac ${ }^{7}$; Amit Mistry ${ }^{8,9}$; Brendon Stubbs $10,11,12$; Lee Smith ${ }^{1}$

Mike Trott - PhD candidate, Anglia Ruskin University mike.trott@pgr.anglia.ac.uk $+447843305609$

${ }^{1}$ Cambridge Centre for Sport and Exercise Sciences, Anglia Ruskin University, Compass House, Cambridge, CB1 1PT; ORCID ID: 0000-0001-5978-3407

Sarah Jackson - Senior Research Associate

${ }^{2}$ Department of Behavioural Science and Health, University College London, London, WC1E 7HB

Joseph Firth

${ }^{3}$ NICM Health Research Institute, Western Sydney University, Westmead, Australia ${ }^{4}$ Division of Psychology and Mental Health, University of Manchester, Manchester, UK ${ }^{5}$ Centre for Youth Mental Health, University of Melbourne, Melbourne, Australia

Louis Jacob

${ }^{6}$ Faculty of Medicine, University of Versailles Saint-Quentin-en-Yvelines, Montigny-leBretonneux 78180, France

Igor Grabovac - Resident Physician

${ }^{7}$ Department of Social and Preventive Medicine, Centre for Public Health, Medical University of Vienna, Kinderspitalgasse 15/1, 1090 Vienna, Austria

Amit Mistry

${ }^{7}$ Eating Disorders Service, Barnet, Enfield \& Haringey Mental Health Trust

${ }^{8}$ RCPsych Sport \& Exercise Psychiatry Special Interest Group

Brendon Stubbs

${ }^{9}$ Positive ageing research institute (PARI), Anglia Ruskin University

${ }^{10}$ Physiotherapy Department, South London and Maudsley NHS Foundation Trust, Denmark Hills, London SE5 8AZ, United Kingdom;

${ }^{11}$ Department of Psychological Medicine, Institute of Psychiatry, Psychology and Neuroscience, King's College London, De Crespigny Park, London, Box, SE5 8AF, United Kingdom

Lee Smith

The Cambridge Centre for Sport and Exercise Sciences, Anglia Ruskin University, Cambridge UK

Word Count: 3,149

Conflict of Interests: None 


\section{Abstract (230/250)}

Background: Exercise addiction is associated with multiple adverse outcomes and can be classified as co-occurring with an eating disorder, or a primary condition with no indication of eating disorders. We conducted a meta-analysis exploring the prevalence of exercise addiction in adults with and without indicated eating disorders.

Methods: A systematic review of major databases and grey literature was undertaken from inception to 30/04/2019. Studies reporting prevalence of exercise addiction with and without indicated eating disorders in adults were identified. A random effect meta-analysis was undertaken, calculating odds ratios for exercise addiction with versus without indicated eating disorders.

Results: Nine studies with a total sample of 2140 participants (mean age $=25.06 ; 70.6 \%$ female) were included. Within these, 1732 participants did not show indicated eating disorders (mean age $=26.4 ; 63.0 \%$ female) and 408 had indicated eating disorders (mean age $=23.46 ; 79.2 \%$ female). The odds ratio for exercise addiction in populations with versus without indicated eating disorders was $3.71\left(95 \% \mathrm{CI} 2.00-6.89 ; \mathrm{I}^{2}=81 ; p=<0.001\right)$. Exercise addiction prevalence in both populations differed according to the measurement instrument used.

Discussion: Exercise addiction occurs more than three and a half times as often as a comorbidity to an eating disorder than in people without an indicated eating disorder. The creation of a measurement tool able to identify exercise addiction risk in both populations would benefit researchers and practitioners by easily classifying samples.

Key words: exercise addiction; exercise dependence; addiction; pathological exercise; eating disorders; disordered eating 


\section{Introduction}

Regular and sustained participation in physical activity and exercise (one domain of physical activity) has been shown to yield several positive health outcomes, including improvements in mental health conditions [1], cardio-vascular disease [2] and wellbeing [3]. There is evidence, however, suggesting that for a sub-set of people exercise can become obsessive, or compulsive (or both), to a point where negative health outcomes are experienced, with physical outcomes including bone fractures, psychological outcomes including increased anxiety, and social outcomes including the detriment of social relationships and financial debt [4]. Several terms have been used to describe the phenomenon, including 'exercise dependence' and 'compulsive exercise' [5,6]. Unfortunately, several authors have failed to provide definitions for these terms, making the interpretation of findings in the related literature challenging [7]. In this paper the term exercise addiction (EA) will be used, as it has been suggested as the most appropriate as it includes aspects of dependence and compulsion $[8,9]$, and can be defined as 'a morbid pattern of behaviour in which the habitually exercising individual loses control over his or her exercise habits and acts compulsively, exhibits dependence, and experiences negative consequences to health as well as in his or her social and professional life'[7].

Early conceptualization in this area suggested a distinction between being highly committed to exercise and EA, with committed, non-EA, subjects exercising mainly for extrinsic rewards, not seeing exercise as central to their life, and suffering fewer and/or less severe symptoms of withdrawal upon cessation [10]. Concurrently, EA subjects exercise for intrinsic rewards, seeing exercise as central to their life, and suffer severe psychological and physiological withdrawal upon cessation [11]. Many theoretical models have been proposed to explain EA, including the Sympathetic Arousal Hypothesis [12] , the Cognitive Appraisal Hypothesis [13], the IL-6 model [14], Four Phase model [15], Biopsychosocial model [16]. Furthermore, Egorov \& Szabo [17] updated the Cognitive Appraisal Hypothesis with their Interactional Model of EA. Disparities between these models indicate a lack of etiologic consensus amongst researchers, which could be one reason why the phenomenon has not been officially classified as a behavioural disorder in The Diagnostic and Statistical Manual of Mental Disorders 5 [18] or the International Classification of Diseases 11th Revision [19]. 
Several screening measures have been developed for assessing risk of EA, with earlier ones lacking underlying theoretical frameworks, including the Obligatory Exercise Questionnaire (OEQ) [20] and the Exercise Dependence Questionnaire (EDQ) [21]. More recent screening measures have used underlying theoretical models, such as the Exercise Dependence Scale (EDS) [22], which uses Diagnostic and Statistical Manual of Mental Disorders 4 [23] criteria for substance abuse, and the Exercise Addiction Inventory (EAI) [24], based on Brown's $[25,26]$ components of behavioural addictions. Currently there is no consensus as to which questionnaire is the most appropriate, however the most commonly used in recent studies are the EAI and the EDS [7].

EA has been shown to be highly prevalent in populations that have either indicated or clinically diagnosed eating disorders (EDs), with prevalence rates in these populations ranging from $29 \%-80 \%$ [27,28]. This is supported by Berczik et al.'s [9] classification of EA being sandwiched between 'body-dysmorphic disorder' and 'anorexia nervosa' on Hollander and Wong's [29] compulsive-obsessive spectrum. Of the different types of EDs, in-patients with clinically diagnosed restricting type anorexia nervosa (AN) have been shown to have higher prevalence rates of EA (80\%) when compared with binge/purging type AN (43.3\%), purging type bulimia nervosa (BN; 39.3\%), and EDs not otherwise specified (EDNOS; $31.9 \%$ ) [30]. High prevalence of EA in patients with AN is of particular concern as these subjects have been shown to have the highest mortality rates of all EDs [31-33], as well as having an increased risk of osteopenia, osteoporosis, and related fractures [34]. It has been reported that subjects with indicated EDs and EA often present with stress fractures and engage in excessive exercising despite injury, with some subjects reporting exercising because it feels like a compulsion rather than for enjoyment $[35,36]$. Considering that weight gain is one of the primary aims of treatment of patients with EDs (particularly AN) [37,38], excessive exercise can result in longer periods to achieve the desired weight gain, which can be costly from a service provision prospective.

EA has also been shown to be prevalent in populations that show no evidence of indicated EDs (failing to reach published cut-off in ED testing questionnaires). For instance, a recent meta-analysis found $11.4 \%$ of health club users had EA in the absence of indicated EDs [39] Some primary studies have also shown significant differences between prevalence rates of EA with and without indicated EDs, with EA in the absence of EDs showing consistently lower prevalence rates than subjects with indicated EDs $[27,28]$. Furthermore, a recent meta- 
analysis explored the prevalence of EA in different populations, however offers no information on the ED status of the populations [40], making it unclear if the prevalence of EA differs by ED status.

Despite the potential differences in the underlying prevalence and potential adverse events of EA between those without and without indicated EDs, it is unknown whether EA risk differs substantially in subjects with and without indicated ED. Moreover, pooled prevalence rates and differences between pooled prevalence rates are unknown. Therefore, the primary aim of this study was, using meta-analytic techniques, to calculate ORs for EA in subjects with and without ED symptomology, and systematically compare the prevalence of EA according to EA measurement tools. Understanding this is essential to understanding more about these conditions, and could inform the creation of new measurement tools, as well as informing the development of targeted interventions. Considering that primary studies have reported that the prevalence of EA with indicated EDs is higher than those without indicated EDs [27,28], we hypothesised that when comparing studies systematically we would find that EA is more prevalent in subjects with indicated EDs than without. 


\section{Method}

This systematic review was conducted according to the Strengthening the Reporting of Observational Studies in Epidemiology [STROBE] criteria and the recommendations in the Preferred Reporting Items for Systematic Reviews and Meta-Analyses [PRISMA] statement $[41,42]$.

\subsection{Search strategy}

Two investigators (MT, LS) searched PsycINFO, Medline, SportDiscuss and Open Grey from inception to 30/04/19 for articles written in English. The search terms (title of article) used were (exercise OR physical activity OR fitness OR sport OR sports) and (addition OR dependence OR dependency OR compulsion OR addict) or (maladaptive OR excessive OR compulsive OR obligatory OR obsessive) and (exercise OR physical activity OR fitness OR exerciser OR exercisers OR sport OR sports). The reference lists of the articles included in the analysis were hand-searched to identify additional literature, and conference abstracts were also considered.

\subsection{Study selection}

Titles and abstracts were independently assessed by two authors (MT, LS) for eligibility against the inclusion and exclusion criteria.

\section{Inclusion Criteria}

Articles were included that met the following criteria:

1. Studies that reported an EA with and without indicated EDs OR or statistics sufficient to calculate such an OR;

2. Written in English;

3. In adults $(\geq 18$ years);

4. That measured the prevalence of EA in any population using any validated measuring tool of EA with established cut-offs (as per original authors' guidelines) that define subjects as at risk of EA;

5. Tested for indicated EDs using a validated measure; 
6. That used the same study population to determine EA prevalence rates in indicated and non-indicated ED populations (to eliminate population bias).

Exclusion Criteria

1. Non-adults ( $<18$ years) 


\subsection{Data extraction}

The following information was extracted by the lead author including: demographic (age, sex, body mass index [BMI]) and prevalence (total EA with and without indicated EDs $n$, EA with and without indicated EDs events $n$, measuring instrument of EA, measuring instrument of ED) data, and missing information was obtained where possible by contacting lead authors (see acknowledgments). If prevalence data were missing and the authors did not respond/have access to the data (two attempted contacts to authors over a one-month period), these studies were excluded. Prevalence data was then converted into ORs. Studies with missing demographic data, but full EA with and without indicated ED prevalence data, were included. Subjects were then categorised into two groups: subjects that failed to meet published cut-offs (as defined by the original author article) for EDs in the non-indicated ED group, and subjects that scored over the published cut offs for EDs in the indicated ED group. In both ED status sub-groups, subjects that met the published cut-offs for EA were respectively categorised as EA.

\subsection{Meta-analysis}

A random-effects model was conducted, weighting studies based on the inverse variance, and calculating odds ratios (ORs) and prevalence rates with 95\% confidence intervals (CIs) using Comprehensive Meta-Analysis version 3 [43]. The primary aim was to calculate ORs of EA in populations with and without indicated EDs. The meta-analysis was conducted in the following steps: 1. ORs of EA comparing those with and without indicated EDs were calculated with $95 \%$ CIs using a mixed effects analysis. 2. Heterogeneity was assessed with the Cochrane $Q$ [44] and $I^{2}$ [45] statistics for all analyses. 3. Sub-group analysis comparing ORs of EA in populations with and without indicated ED by EA measurement tool. Publication bias was assessed with a visual inspection of funnel plots and with the BeggMazumdar Kendall's tau [46] and Egger bias test [47]. As per recommendations from Fu et al. and Sterne et al. [48,49], these tests were only conducted if the number of studies exceeded ten. If the Egger bias test was significant, to adjust for potential publication bias, the trim-and-fill adjusted analysis was used to remove the most extreme small studies from the positive side of the funnel plot and effect sizes re-calculated, until the funnel plot was symmetrical with the new effect size [50]. A sensitivity analyses was calculated around the 
primary analyses, using a one-study removed method. This was to detect whether the observed effect was overly influenced by any one study. 


\section{Results}

The literature search yielded 1375 results, of which 369 were removed as duplicates, leaving 1,006 studies screened using title and abstract. From the 1,006 titles and abstracts screened, 223 studies were selected for full-text review. Of the 223 studies reviewed, 9 studies were eligible for inclusion. Reasons for exclusion are shown in Figure 1 and descriptive statistics for included studies are shown in Table 1. From the 9 included studies, there were a total of 2,140. 1,732 subjects scored below published ED cut-offs and were categorised as the nonindicated ED group, of which 342 scored above EA cut-offs are were defined as exercise addicted. 408 subjects scored above the published ED cut-offs and were categorised as the indicated ED group, of which 225 scored above EA cut-off and were defined as EA. The methods of measuring EA were the Exercise Dependence Questionnaire [21], the Exercise Dependence Scale [22], the Obligatory Exercise Questionnaire [20], and the Exercise Addiction Inventory [24]. The methods of measuring for indicated EDs were the Eating Attitudes Test 40 [51], the Eating Attitudes Test 26 [52], the Eating Disorder Examination Questionnaire [53], the Eating Disorder Inventory-2 [54], and the SCOFF Questionnaire [55].

\subsection{Meta-analysis results}

\subsubsection{ORs of EA in populations with and without indicated EDs}

The pooled OR of EA in populations with indicated EDs compared to those without indicated EDs was 3.71 (95\% CI 2.00-6.89; $\mathrm{I}^{2}=81.159 ; p=<0.001$; Egger bias $=2.054 p=0.480$; trimand-fill adjustment not required). The meta-analysis forest plot is shown in Figure 2.

\subsubsection{Sensitivity analysis}

The direction or significance of the ORs was not changed by the sensitivity analysis, with point estimates ranging from 3.019-4.755. One study [56] had a large effect of the magnitude of the result, with the removal of this study yielding an estimate of 4.755 (95\% CI 2.875 $7.863 ; p=<0.001$ ) 
3.1.3 Sub-group analysis of EA prevalence in populations with and without indicated ED by EA measurement type.

As shown in Table 2, the OR of EA among subjects with indicated vs no-indicated EDs was highest when measured with the OEQ (6.9; 95\%CI 2.2-21.8), followed by the EAI (4.2; $95 \% \mathrm{CI}=1.4-12.2)$, the $\mathrm{EDS}(3.9 ; 95 \% \mathrm{CI}=1.2-12.5)$, with the EDQ yielding the lowest $\mathrm{OR}$ (2.4; 95CI 1.0-5.7). 


\section{Discussion}

This meta-analysis of 9 studies demonstrated that the OR of EA in populations with vs without indicated EDs was 3.7. The sensitivity analysis showed that the direction and significance of the findings were unchanged when one study was removed. ORs also differed largely in both populations depending on the EA measurement tool being used.

Subjects who score above published cut-offs for EDs are over three times more likely to be at risk of EA, with observed prevalence rates in subjects with indicated EDs comparing well with EA studies conducted on clinical ED populations [35,57]. One possible reason is that excessive exercise has been consistently shown to be an inherent part of several types of EDs, with patients demonstrating aversions to weight gain and showing obsessions towards not gaining weight [58]. Furthermore, ED subjects have been shown to score higher on addictive personality measures and obsessive-compulsive behaviours [59]. Considering this, future studies that use clinically diagnosed ED patients (of all types of EDs) would be useful. Given that EA can be secondary to an ED and with the results of this study suggesting that subjects who show ED symptomology have significantly higher prevalence of EA, this adds to the evidence suggesting that practitioners working with ED patients should consider monitoring exercise levels a priority, as ED patients have been shown to suffer from serious medical conditions as a result of excessive exercise, such as fractures, increased rates of cardiovascular disease in younger patients and increased overall mortality [34].

The large difference in EA prevalence observed between indicated and non- indicated ED groups adds to evidence suggesting that ED symptomology should be screened for in all studies that measure EA. The current meta-analysis excluded 93 studies that failed to measure ED symptomology, which agrees with recent reviews suggested that the EA literature has not readily distinguished between ED status as standard practice [60]. Currently, to measure EA and screen for EDs, two questionnaires are needed. Future work to create a new tool that screens for EDs and EA in one single tool would be beneficial. Not only would this benefit researchers by only having to use one tool to categorise EA with and without indicated EDs, it could also be beneficial in both a clinical and public health settings by highlighting at-risk subjects earlier, which could inform (in ED subjects) specialized nursing observation and bathroom supervision to regulate EA behaviours be implemented earlier in treatment. Moreover, earlier categorisation of EA with an indicated ED has the 
potential to allow practitioners such as general practitioners, physiotherapists and health practitioners to therapeutically explore EA at an earlier point.

The large differences in prevalence rates by EA measurement tool are a further indication that differing EA measurement tools are measuring different aspects of the same phenomenon, with the two tools with no underlying theories (OEQ and EDQ) yielding higher ORs than the two tools that use underlying addiction theories (EAI and EDS). To date, no studies have been conducted comparing subjects who score above the published thresholds for different EA measurement tools and clinical interviews to determine the sensitivity of these tools. It is therefore difficult to recommend a specific measurement tool. It is the authors' view that the EAI and EDS be used until such studies are conducted, as they both are based on underlying theories of addiction and have been described as comparable by several authors $[8,9]$.

Limited research has been conducted exploring possible treatments for EA. Much of the focus of treatment has been focussed around cognitive behaviour therapies, yet their effectiveness has been shown to be limited [61]. Adams, Miller and Kraus [62] suggested specific therapeutic guidelines for subjects with EA, although Lichtenstein et al. [63] comment that studies to test these guidelines are sparse. Although one individual pharmacological case study has been conducted with an EA patient showing lower EAI scores post-4 weeks of taking an anti-psychotic drug (Quetiapine)[64], no other pharmacological treatments have been explored. Due to the higher rates of serious injury and mortality amongst ED patients, treatment for ED should be prioritised over treatment specifically for EA, although further research is required to explore the relationships between the two so that effective treatments can be refined and/or developed.

While this meta-analysis is the first to measure EA prevalence rates in populations with and without indicated EDs, the findings should be considered within the limitations of this study. Firstly, the heterogeneity of population groups and measurement tools (for EA and ED) and very small sample sizes means that this should only be considered a broad overview; further studies are needed to determine more accurate prevalence rates, using homogeneous tools. Secondly, the use of questionnaires for testing for EDs has limited applications to clinical diagnoses. Thirdly, the use of the questionnaires in this study precluded the subcategorisation of different types of EDs, which is relevant as previous research has shown 
prevalence rates to differ depending on the type of ED [30]. Moreover, athletic subjects who use ED testing questionnaires have been shown to under-report due to possible stigmatization, with false-positives a possibility [53,65]. Lastly, there was high heterogeneity which we could not fully explain. 


\section{What is already known?}

It is known that exercise addiction exists both as a primary condition without indicated eating disorders, and as a secondary condition to an eating disorder. What is unknown is the magnitude of risk for EA with an indicated eating disorder vs no-indicated eating disorders. 


\section{What does this study add?}

Subjects with indicated eating disorders are over 3.5 times more likely to suffer from addiction to exercise than their non-indicated eating disorder counterparts. Due to the higher risk of mortality in subjects with eating disorders, this study adds to the evidence that exercise levels should be closely monitored in these populations. Furthermore, the absence of eating disorders does not preclude the risk of being addicted to exercise. Further study in this area to explore treatments and the effect on quality of life is warranted. 


\section{Conclusion}

The OR for EA in populations with vs without indicated EDs is 3.7, with EA being significantly more prevalent in subjects with indicated EDs than in subjects without indicated EDs, adding to the evidence that practitioners working with ED subjects should closely monitor exercise levels. However, even in those showing no indicated EDs, EA is of notable prevalence - EA should not be discounted entirely on the basis of no indicated ED behaviours. It is also recommended that all future research exploring the prevalence of EA test for EDs to determine accurate prevalence rates. 


\section{Acknowledgments}

The authors wish to express their gratitude to Malcolm Bond, Kyle De Young, Kelsey Serier and Laura Di Lodovico for their help and support in the collecting of raw data for analysis. 


\section{References}

1. Mikkelsen K, Stojanovska L, Polenakovic M, Bosevski M, Apostolopoulos V. Exercise and mental health. Maturitas. Elsevier; 2017;106:48-56.

https://doi.org/10.1016/j.maturitas.2017.09.003

2. Wilson MG, Ellison GM, Cable NT. Basic science behind the cardiovascular benefits of exercise. Br J Sport Med. BMJ Publishing Group Ltd and British Association of Sport and Exercise Medicine; 2016;50:93-9. https://doi.org/10.1136/bjsports-2014-306596rep

3. Mandolesi L, Polverino A, Montuori S, Foti F, Ferraioli G, Sorrentino P, et al. Effects of physical exercise on cognitive functioning and wellbeing: biological and psychological benefits. Front Psychol. Frontiers; 2018;9:509. https://doi.org/10.3389/fpsyg.2018.00509

4. Landolfi E. Exercise addiction. Sport Med; 2013;43:111-9.

https://doi.org/10.1007/s40279-012-0013-x

5. Leuenberger A. Endorphins, exercise, and addictions: a review of exercise dependence. Prem J Undergrad Publ Neurosci. 2006;3:1-9. Available from https://impulse.appstate.edu/sites/impulse.appstate.edu/files/2006_06_05_Leuenberger.pdf

6. Adams J. Understanding exercise dependence. J Contemp Psychother; 2009;39:231-40. https://doi.org/10.1007/s10879-009-9117-5

7. Szabo A, Griffiths MD, de La Vega Marcos R, Mervó B, Demetrovics Z. Methodological and Conceptual Limitations in Exercise Addiction Research. Yale J Biol Med; 2015;88:3038. Available from:

http://search.ebscohost.com/login.aspx?direct=true $\& \mathrm{db}=\mathrm{cmedm} \& \mathrm{AN}=26339214 \&$ site=ehost -live

8. Goodman A. Addiction: definition and implications. Br J Addict. Wiley Online Library; 1990;85:1403-8. https://doi.org/10.1111/j.1360-0443.1990.tb01620.x

9. Berczik K, Szab A, Griffiths MD, Kurimay T, Kun B, Urbán R, et al. Exercise Addiction: Symptoms, Diagnosis, Epidemiology, and Etiology. Subst Use Misuse; 2012;47:403-17. https://doi.org/10.3109/10826084.2011.639120

10. de Coverley Veale DM. Exercise dependence. Br J Addict; 1987;82:735-40. https://doi.org/10.1111/j.1360-0443.1987.tb01539.x

11. Sachs ML. Running Addiction. In: Sachs M, Sachs M, editors. Psychol Run. Champaign, IL: Human Kinetics; 1981. p. 116-26.

12. Thompson JK, Blanton P. Energy conservation and exercise dependence: a sympathetic arousal hypothesis. Med Sci Sports Exerc. 1987; https://doi.org/10.1249/00005768198704000-00005

13. Szabo A. The impact of exercise deprivation on well-being of habitual exercisers. Aust $\mathbf{J}$ Sci Med Sport; 1995;27:68-75. Available from: http://articles.sirc.ca/search.cfm?id=390518 
14. Hamer M, Karageorghis CI. Psychobiological mechanisms of exercise dependence. Sports Med; 2007;37:477-84. https://doi.org/10.2165/00007256-200737060-00002

15. Freimuth M, Moniz S, Kim SR. Clarifying exercise addiction: differential diagnosis, cooccurring disorders, and phases of addiction. Int J Environ Res Public Health; 2011;8:406981. https://doi.org/10.3390/ijerph8104069

16. McNamara J, McCabe MP. Striving for success or addiction? Exercise dependence among elite Australian athletes. J Sports Sci; 2012;30:755-66.

https://doi.org/10.1080/02640414.2012.667879

17. Egorov AY, Szabo A. The exercise paradox: An interactional model for a clearer conceptualization of exercise addiction. J Behav Addict; 2013;2:199-208.

https://doi.org/10.1556/jba.2.2013.4.2

18. American Psychiatric Association. DSM-V. Am. J. Psychiatry. 2013.

19. WHO. WHO | International Classification of Diseases, 11th Revision (ICD-11). Who. 2019.

20. Pasman L, Thompson JK. Body image and eating disturbance in obligatory runners, obligatory weightlifters, and sedentary individuals. Int J Eat Disord; 1988;7:759-69. https://doi.org/10.1002/1098-108x(198811)7:6\%3C759::aid-eat2260070605\%3E3.0.co;2-g

21. Ogden J, Veale D, Summers Z. The development and validation of the Exercise Dependence Questionnaire. Addict Res; 1997;5:343-55.

https://doi.org/10.3109/16066359709004348

22. Hausenblas HA, Downs DS. How much is too much? The development and validation of the exercise dependence scale. Psychol Health; 2002;17:387-404.

https://doi.org/10.1080/0887044022000004894

23. Diagnostic and Statistical Manual of Mental Disorders, Fourth Edition, Text Revision (DSM-IV-TR). 2000.

24. Terry A, Szabo A, Griffiths M. The exercise addiction inventory: A new brief screening tool. Addict Res Theory; 2004;12:489-99. https://doi.org/10.1080/16066350310001637363

25. Brown RIF. Some contributions of the study of gambling to the study of other addictions. Gambl Behav Probl Gambl. 1993; 1:241-72

26. Brown RIF. A theoretical model of the behavioural addictions-applied to offending. Addicted to crime. 1997;13-65.

27. Dalle Grave R, Calugi S, Marchesini G. Compulsive exercise to control shape or weight in eating disorders: prevalence, associated features, and treatment outcome. Compr Psychiatry; 2008;49:346-52. https://doi.org/10.1016/j.comppsych.2007.12.007

28. Bratland-Sanda S, Martinsen EW, Rosenvinge JH, Rø O, Hoffart A, Sundgot-Borgen J. Exercise dependence score in patients with longstanding eating disorders and controls: the 
importance of affect regulation and physical activity intensity. Eur Eat Disord Rev J Eat Disord Assoc; 2011;19:249-55. https://doi.org/10.1002/erv.971

29. Hollander E, Kwon JH, Stein DJ, Broatch J, Rowland CT, Himelein CA. Obsessivecompulsive and spectrum disorders: Overview and quality of life issues. Journal of Clinical Psychiatry. 1996;57(SUPPL. 8):3-6.

30. Dalle Grave R. Features and management of compulsive exercising in eating disorders. Phys Sportsmed; 2009;37:20-8. https://doi.org/10.3810/psm.2009.10.1725

31. Smink FRE, van Hoeken D, Hoek HW. Epidemiology of Eating Disorders: Incidence, Prevalence and Mortality Rates. Curr Psychiatry Rep; 2012;14:406-14.

https://doi.org/10.1007/s11920-012-0282-y

32. Sauchelli S, Arcelus J, Granero R, Jiménez-Murcia S, Agüera Z, Del Pino-Gutiérrez A, et al. Dimensions of Compulsive Exercise across Eating Disorder Diagnostic Subtypes and the Validation of the Spanish Version of the Compulsive Exercise Test. Front Psychol; 2016;7:1852. https://doi.org/10.3389/fpsyg.2016.01852

33. Arcelus J, Mitchell AJ, Wales J, Nielsen S. Mortality Rates in Patients With Anorexia Nervosa and Other Eating Disorders: A Meta-analysis of 36 Studies. JAMA Psychiatry. 2011;68:724-31. https://doi.org/10.1001/archgenpsychiatry.2011.74

34. Solmi M, Veronese N, Correll CU, Favaro A, Santonastaso P, Caregaro L, et al. Bone mineral density, osteoporosis, and fractures among people with eating disorders: a systematic review and meta-analysis. Acta Psychiatr Scand; 2016;133:341-51.

https://doi.org/10.1111/acps.12556

35. Klein DA, Bennett AS, Schebendach J, Foltin RW, Devlin MJ, Walsh BT. Exercise "addiction" in anorexia nervosa: model development and pilot data. CNS Spectr; 2004;9:531-7. https://doi.org/10.1017/s1092852900009627

36. Laban MM, Wilkins JC, Sackeyfio AH, Taylor RS. Osteoporotic stress fractures in anorexia nervosa: etiology, diagnosis, and review of four cases. Arch Phys Med Rehabil. Elsevier; 1995;76:884-7. https://doi.org/10.1016/s0003-9993(95)80558-3

37. Misra M, Klibanski A. Bone health in anorexia nervosa. Curr. Opin. Endocrinol. Diabetes Obes. 2011. https://doi:10.1097/MED.0b013e32834b4bdc

38. Kaye WH, Gwirtsman HE, Obarzanek E, George DT. Relative importance of calorie intake needed to gain weight and level of physical activity in anorexia nervosa. Am J Clin Nutr. 1988; https://doi.org/10.1093/ajcn/47.6.989

39. Trott, M; Jackson, S; Firth, J; Stubbs, B; Smith L. Exercise addiction prevalence and correlates in the absence of eating disorder symptomology. Journal of Sports Sciences:2019;37: 1-93. https://doi.org/10.1080/02640414.2019.1671688

40. Di Lodovico L, Poulnais S, Gorwood P. Which sports are more at risk of physical exercise addiction: A systematic review. Addict Behav; 2019;93:257-62.

https://doi.org/10.1016/j.addbeh.2018.12.030 
41. Liberati A, Altman DG, Tetzlaff J, Mulrow C, Gøtzsche PC, Ioannidis JPA, et al. The PRISMA statement for reporting systematic reviews and meta-analyses of studies that evaluate health care interventions: explanation and elaboration. PLoS Med; 2009;6:e1000100. https://doi.org/10.7326/0003-4819-151-4-200908180-00136

42. Von Elm E, Altman DG, Egger M, Pocock SJ, Gøtzsche PC, Vandenbroucke JP, et al. The Strengthening the Reporting of Observational Studies in Epidemiology (STROBE) statement: guidelines for reporting observational studies. PLoS Med; 2007;4:e296. https://doi.org/10.7554/elife.08500.009

43. Borenstein M, Hedges L, Higgins J, Rothstein H. Comprehensive Meta Analysis. Englewood, NJ: Biostat; 2013.

44. Cochran WG. The combination of estimates from different experiments. Biometrics. JSTOR; 1954;10:101-29. https://doi.org/10.2307/3001666

45. Higgins JPT, Thompson SG. Quantifying heterogeneity in a meta-analysis. Stat Med. Wiley Online Library; 2002;21:1539-58. https://doi.org/10.1002/sim.1186

46. Begg CB, Mazumdar M. Operating Characteristics of a Rank Correlation Test for Publication Bias. Biometrics. 1994; https://doi.org/10.2307/2533446

47. Egger M, Smith GD, Schneider M, Minder C. Bias in meta - analysis detected by a simple, graphical test. BMJ Br Med J. 1997; https://doi.org/10.1136/bmj.315.7109.629

48. Fu R, Gartlehner G, Grant M, Shamliyan T, Sedrakyan A, Wilt TJ, et al. Conducting quantitative synthesis when comparing medical interventions: AHRQ and the Effective Health Care Program. J. Clin. Epidemiol. 2011. https://doi.org/10.1016/j.jclinepi.2010.08.010

49. Sterne JA, Egger M, Moher D. Addressing Reporting Biases. Cochrane Handb Syst Rev Interv Cochrane B Ser. 2008. https://doi.org/10.1002/9780470712184.ch10

50. Duval S, Tweedie R. Trim and fill: A simple funnel-plot-based method of testing and adjusting for publication bias in meta-analysis. Biometrics. 2000;

https://doi.org/10.1111/j.0006-341x.2000.00455.x

51. Garner DM, Garfinkel PE. The Eating Attitudes Test: An index of the symptoms of anorexia nervosa. Psychol Med. Cambridge University Press; 1979;9:273-9.

https://doi.org/10.1017/s0033291700030762

52. Garner DM, Olmsted MP, Bohr Y, Garfinkel PE. The Eating Attitudes Test: psychometric features and clinical correlates. Psychol Med; 1982;12:871-8. https://doi.org/10.1017/s0033291700049163

53. Fairburn CG, Beglin SJ. Assessment of eating disorders: Interview or self-report questionnaire? Int J Eat Disord; 1994;16:363-70. https://doi.org/10.1002/1098108X(199412)16:4\%3C363::AID-EAT2260160405\%3E3.0.CO;2-\%23 
54. Garner DM. Eating disorder Inventory-2: professional Manual. Florida: Psychological Assessment Resources. Inc; 1991.

55. Morgan JF, Reid F, Lacey JH. The SCOFF questionnaire: assessment of a new screening tool for eating disorders. Bmj. British Medical Journal Publishing Group; 1999;319:1467-8. https://doi.org/10.1136/bmj.319.7223.1467

56. Grandi S, Clementi C, Guidi J, Benassi M, Tossani E. Personality characteristics and psychological distress associated with primary exercise dependence: An exploratory study. Psychiatry Res; 2011;189:270-5. https://doi.org/10.1016/j.psychres.2011.02.025

57. Dalle Grave R, Grave RD. Excessive and compulsive exercises in eating disorders: Prevalence, associated features, and management. Dir Psychiatry; 2008;28:273-82. https://doi.org/10.1016/j.comppsych.2007.12.007

58. Davis C, Katzman DK, Kaptein S, Kirsh C, Brewer H, Kalmbach K, et al. The prevalence of high-level exercise in the eating disorders: Etiological implications. Compr Psychiatry; 1997;38:321-6. https://doi.org/10.1016/s0010-440x(97)90927-5

59. Davis $\mathrm{C}$, Claridge $\mathrm{G}$. The eating disorders as addiction: A psychobiological perspective. Addict Behav;1998;23:463-75. https://doi.org/10.1016/S0306-4603(98)00009-4

60. Symons Downs D, MacIntyre RI, Heron KE. Exercise addiction and dependence. In: Anshel MH, Petruzzello SJ, Labbé EE, editors. APA Handb Sport Exerc Psychol Vol 2 Exerc Psychol Vol 2; 2019. p. 589-604. https://doi.org/10.1037/0000124-030

61. Weinman, A, Weinman, Y. Exercise addiction- diagnosis, bio-psychological mechanisms and treatment issues. Curr Pharm Des; 2014;20:4062-9.

https://doi.org/10.2174/13816128113199990614

62. Adams JM, Miller TW, Kraus RF. Exercise dependence: Diagnostic and therapeutic issues for patients in psychotherapy. J Contemp; 2003;33:93-107.

https://doi.org/10.1023/A:1022883104269

63. Lichtenstein MB, Hinze CJ, Emborg B, Thomsen F, Hemmingsen SD. Compulsive exercise: links, risks and challenges faced. Psychol Res Behav; 2017;10:85-95.

https://doi.org/10.2147/prbm.s113093

64. Di Nicola M, Martinotti G, Mazza M, Tedeschi D, Pozzi G, Janiri L. Quetiapine as addon treatment for bipolar I disorder with comorbid compulsive buying and physical exercise addiction. Prog Neuropsychopharmacol Biol Psychiatry; 2010;34:713-4.

https://doi.org/10.1016/j.pnpbp.2010.03.013

65. Sundgot-Borgen J, Torstveit MK. Prevalence of Eating Disorders in Elite Athletes Is Higher Than in the General Population. Clin J Sport Med. 2004;

https://doi.org/10.1097/00042752-200401000-00005

66. Bamber D, Cockerill IM, Carroll D. The pathological status of exercise dependence. Br J Sports Med; 2000;34:125-32. https://doi.org/10.1136/bjsm.34.2.125 
67. Blaydon MJ, Lindner KJ. Eating disorders and exercise dependence in triathletes. Eat Disord. 2002;10:49-60. https://doi.org/10.1080/106402602753573559

68. Blaydon MJ, Linder KJ, Kerr JH. Metamotivational characteristics of exercise dependence and eating disorders in highly active amateur sport participants. Pers Individ Dif; 2004;36:1419-32. https://doi.org/10.1016/s0191-8869(03)00238-1

69. De Young KP, Anderson DA. The importance of the function of exercise in the relationship between obligatory exercise and eating and body image concerns. Eat Behav; 2010;11:62-4. https://doi.org/10.1016/j.eatbeh.2009.09.001

70. Di Lodovico L, Dubertret C, Ameller A. Vulnerability to exercise addiction, sociodemographic, behavioral and psychological characteristics of runners at risk for eating disorders. Compr Psychiatry; 2018;81:48-52.

https://doi.org/10.1016/i.comppsych.2017.11.006

71. Lease HJ, Bond MJ. Correspondence between alternate measures of maladaptive exercise, and their associations with disordered eating symptomatology. J Behav Addict; 2013;2:153-9. https://doi.org/10.1556/jba.2.2013.012

72. Meulemans S, Pribis P, Grajales T, Krivak G. Gender differences in exercise dependence and eating disorders in young adults: a path analysis of a conceptual model. Nutrients; 2014;6:4895-905. https://doi.org/10.3390/nu6114895

73. Serier KN, Smith JE, Lash DN, Gianini LM, Harriger JA, Sarafin RE, et al. Obligatory exercise and coping in treatment-seeking women with poor body image. Eat Weight Disord; 2018; https://doi.org/10.1007/s40519-018-0504-3 
10. Figures 


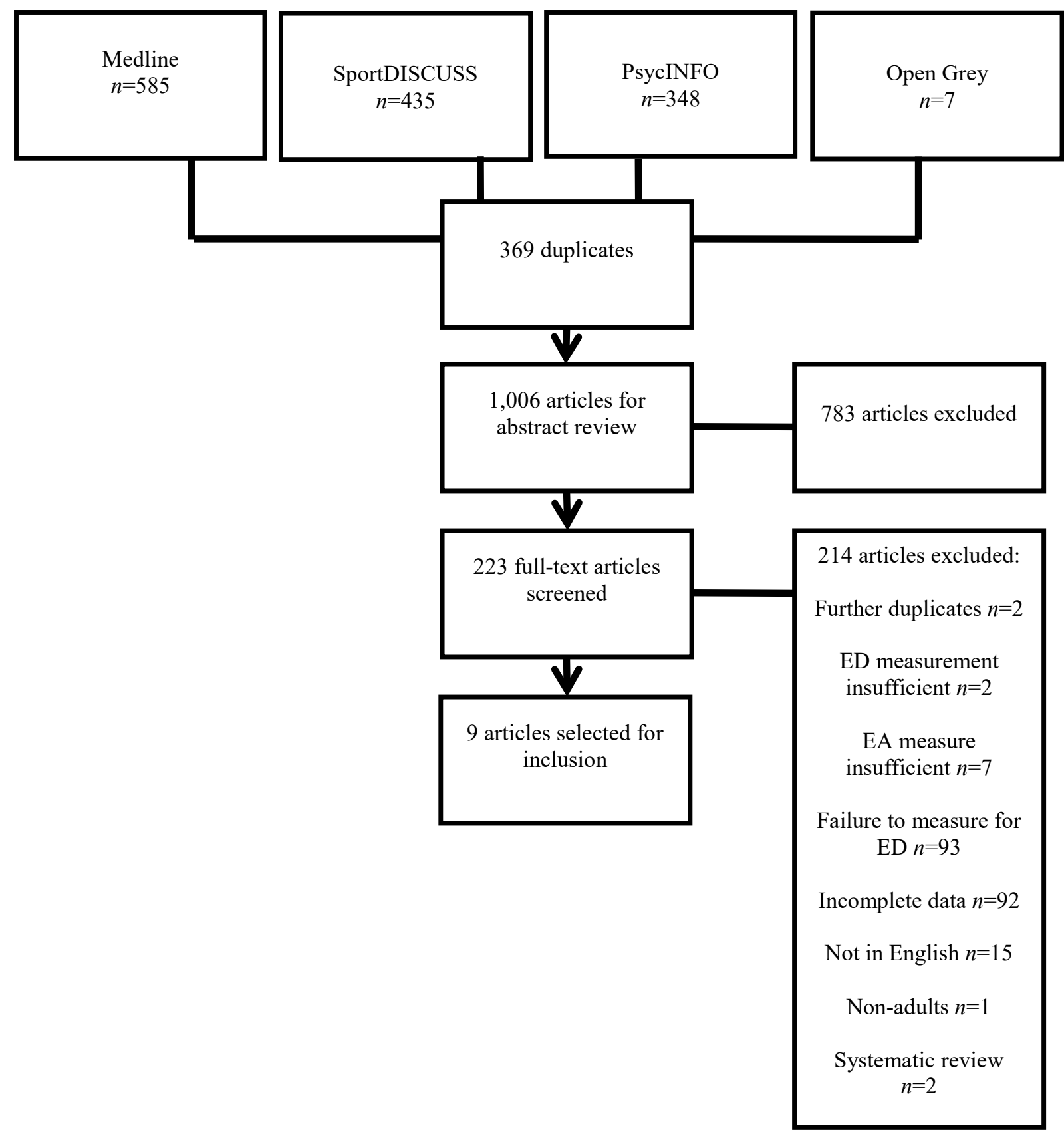


Figure 1: Prisma flowchart of included studies 


\section{Study name}

$\begin{array}{lrrr} & \begin{array}{r}\text { Odds } \\ \text { ratio }\end{array} & \begin{array}{r}\text { Lower } \\ \text { limit }\end{array} & \begin{array}{r}\text { Upper } \\ \text { limit }\end{array} \\ \text { Bamber et al. (2000) } & 4.934 & 2.365 & 10.294 \\ \text { Blaydon et al. (2002) } & 2.067 & 1.078 & 3.962 \\ \text { Blaydon et al. (2004) } & 4.742 & 2.900 & 7.752 \\ \text { De Young and Anderson (2010) } & 6.836 & 2.402 & 19.455 \\ \text { Di Lodovido et al. (2018) } & 4.172 & 1.432 & 12.157 \\ \text { Grandi et al. (2011) } & 0.490 & 0.186 & 1.287 \\ \text { Lease and Bond (2013) } & 16.687 & 8.593 & 32.404 \\ \text { Meulemans et al. (2014) } & 3.884 & 1.206 & 12.508 \\ \text { Serier et al. (2018) } & 2.450 & 0.865 & 6.939 \\ & 3.708 & 1.995 & 6.894\end{array}$

Odds ratio and $95 \% \mathrm{CI}$

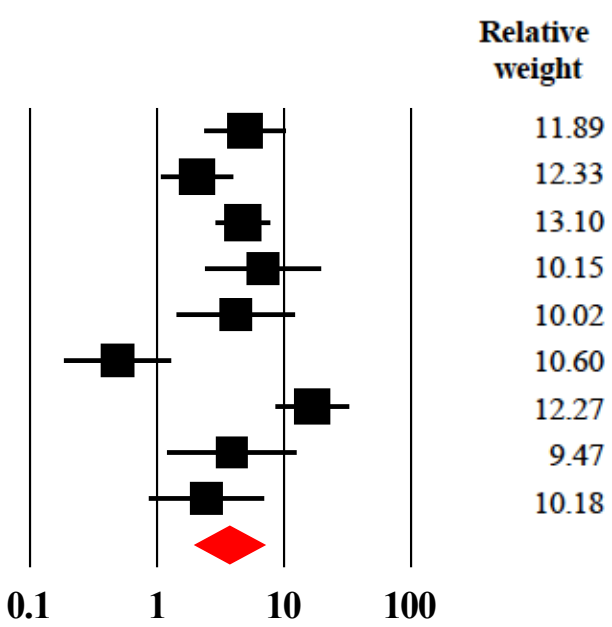

Figure 2: Forest plot showing odds ratios of exercise addiction in populations without vs with indicated eating disorders 


\section{Tables}

Table 1: Descriptive statistics of included articles

\begin{tabular}{|c|c|c|c|c|c|c|c|c|c|c|c|}
\hline Author & $\begin{array}{l}\text { EA odds } \\
\text { Ratio }(95 \% \\
\text { Cl) }\end{array}$ & Sub-group & $\begin{array}{l}\text { Total } \\
n\end{array}$ & $\begin{array}{l}\text { Mean } \\
\text { Age }\end{array}$ & BMI & $\begin{array}{l}\text { Sex (\% } \\
\text { female) }\end{array}$ & Country & Population & $\begin{array}{l}\text { EA } \\
\text { measure }^{\dagger}\end{array}$ & $\begin{array}{l}\text { EA measure } \\
\text { reliability } \\
\text { (Cronbach's alpha) }\end{array}$ & $\begin{array}{l}\text { ED Measure } \\
\text { Used }^{\ddagger}\end{array}$ \\
\hline \multirow[t]{2}{*}{$\begin{array}{l}\text { Bamber et. al. } \\
{[66]}\end{array}$} & \multirow{2}{*}{$\begin{array}{l}4.934 \\
(2.365- \\
10.294)\end{array}$} & $\begin{array}{l}\text { Non- } \\
\text { indicated ED }\end{array}$ & 153 & NR & NR & 100 & \multirow[t]{2}{*}{ UK } & \multirow{2}{*}{$\begin{array}{l}\text { Various (aerobic dance classes; } \\
\text { university and community sports } \\
\text { centres; university cross country and } \\
\text { athletics clubs and local running clubs) }\end{array}$} & \multirow[t]{2}{*}{ EDQ } & \multirow[t]{2}{*}{0.84} & \multirow[t]{2}{*}{ EDE-Q } \\
\hline & & Indicated ED & 41 & NR & NR & 100 & & & & & \\
\hline \multirow[t]{2}{*}{$\begin{array}{l}\text { Blaydon and } \\
\text { Lindner [67] }\end{array}$} & \multirow{2}{*}{$\begin{array}{l}2.067 \\
(1.078- \\
3.962)\end{array}$} & $\begin{array}{l}\text { Non- } \\
\text { indicated ED }\end{array}$ & 113 & NR & NR & 32.69 & \multirow[t]{2}{*}{$\begin{array}{l}\text { Multi- } \\
\text { national }\end{array}$} & \multirow[t]{2}{*}{ Triathletes } & \multirow[t]{2}{*}{$\mathrm{EDQ}$} & \multirow[t]{2}{*}{ NR } & \multirow[t]{2}{*}{ EAT-40 } \\
\hline & & Indicated ED & 58 & NR & NR & 40.54 & & & & & \\
\hline \multirow[t]{2}{*}{$\begin{array}{l}\text { Blaydon and } \\
\text { Lindner [68] }\end{array}$} & \multirow{2}{*}{$\begin{array}{l}4.742 \\
(2.900- \\
7.752)\end{array}$} & $\begin{array}{l}\text { Non- } \\
\text { indicated ED }\end{array}$ & 296 & NR & NR & 27.70 & \multirow[t]{2}{*}{ UK } & \multirow[t]{2}{*}{ Amateur competitive exercisers } & \multirow[t]{2}{*}{ EDQ } & \multirow[t]{2}{*}{ NR } & \multirow[t]{2}{*}{ EAT-40 } \\
\hline & & Indicated ED & 86 & NR & NR & 52.33 & & & & & \\
\hline \multirow[t]{2}{*}{$\begin{array}{l}\text { De Young and } \\
\text { Anderson [69] }\end{array}$} & \multirow{2}{*}{$\begin{array}{l}6.836 \\
(2.402- \\
19.455)\end{array}$} & $\begin{array}{l}\text { Non- } \\
\text { indicated ED }\end{array}$ & 207 & 19 & 24.2 & 49.28 & \multirow[t]{2}{*}{ NR } & \multirow{2}{*}{$\begin{array}{l}\text { Undergraduate students that engage } \\
\text { in 'physical exercise at least } \\
\text { occasionally' }\end{array}$} & \multirow[t]{2}{*}{ OEQ } & \multirow[t]{2}{*}{0.89} & \multirow[t]{2}{*}{ EDE-Q } \\
\hline & & Indicated ED & 21 & 20 & 23.94 & 80.95 & & & & & \\
\hline \multirow{2}{*}{$\begin{array}{l}\text { Di Lodovico, } \\
\text { Dubertret, \& } \\
\text { Ameller [70] }\end{array}$} & \multirow{2}{*}{$\begin{array}{l}4.172 \\
(1.432- \\
12.157)\end{array}$} & $\begin{array}{l}\text { Non- } \\
\text { indicated ED }\end{array}$ & 129 & 30.39 & NR & 46.51 & \multirow[t]{2}{*}{ NR } & \multirow[t]{2}{*}{ Runners } & \multirow[t]{2}{*}{ EAI } & \multirow[t]{2}{*}{ NR } & \multirow[t]{2}{*}{ SCOFF } \\
\hline & & Indicated ED & 25 & 26.72 & $\mathrm{NR}$ & 84.00 & & & & & \\
\hline \multirow[t]{2}{*}{$\begin{array}{l}\text { Grandi et. al. } \\
\text { [56] }\end{array}$} & $\begin{array}{l}0.490 \\
(0.186-\end{array}$ & $\begin{array}{l}\text { Non- } \\
\text { indicated ED }\end{array}$ & 79 & 30 & 21.6 & 57.00 & Italy & Health Club users & $\mathrm{EDQ}$ & 0.92 & EDI-2 \\
\hline & $1.287)$ & Indicated ED & 28 & NR & NR & NR & & & & & \\
\hline $\begin{array}{l}\text { Lease and } \\
\text { Bond [71] }\end{array}$ & $\begin{array}{l}16.687 \\
(8.593-\end{array}$ & $\begin{array}{l}\text { Non- } \\
\text { indicated ED }\end{array}$ & 227 & 23 & 23.35 & 100 & Australia & Health Club users & OEQ & NR & EAT-26 \\
\hline & $32.404)$ & Indicated ED & 75 & 21 & 22.78 & 100 & & & & & \\
\hline
\end{tabular}




\begin{tabular}{|c|c|c|c|c|c|c|c|c|c|c|c|}
\hline \multirow[t]{2}{*}{$\begin{array}{l}\text { Meulemans et. } \\
\text { al. (55) }\end{array}$} & \multirow{2}{*}{$\begin{array}{l}3.884 \\
(1.206- \\
12.508)\end{array}$} & $\begin{array}{l}\text { Non- } \\
\text { indicated ED }\end{array}$ & 480 & 19.76 & 22.14 & 54.12 & \multirow[t]{2}{*}{ USA } & \multirow[t]{2}{*}{$\begin{array}{l}\text { Various undergraduate } \\
\text { and graduate students }\end{array}$} & \multirow[t]{2}{*}{ EDS-R } & \multirow[t]{2}{*}{ NR } & \multirow[t]{2}{*}{ EAT-26 } \\
\hline & & Indicated ED & 41 & 19.7 & 22.07 & 75.61 & & & & & \\
\hline \multirow[t]{2}{*}{$\begin{array}{l}\text { Serier et. al. } \\
\text { [73] }\end{array}$} & \multirow{2}{*}{$\begin{array}{l}2.450 \\
(0.865- \\
6.939)\end{array}$} & $\begin{array}{l}\text { Non- } \\
\text { indicated ED }\end{array}$ & 48 & 36.23 & NR & 100 & \multirow[t]{2}{*}{ USA } & \multirow[t]{2}{*}{$\begin{array}{l}\text { Women seeking help for body- } \\
\text { dissatisfaction }\end{array}$} & \multirow[t]{2}{*}{ OEQ } & \multirow[t]{2}{*}{0.88} & \multirow[t]{2}{*}{ EAT-26 } \\
\hline & & Indicated ED & 22 & 29.86 & NR & 100 & & & & & \\
\hline
\end{tabular}

${ }^{\mathrm{E} E D E}$-Q $=$ Eating Disorders Examination Questionnaire; EAT 26 = Eating Attitudes Test 26; EAT 40 = Eating Attitudes Test 40 EDI-2 = Eating Disorders Inventory 2 
Table 2: Odds ratios of risk of exercise addiction with and without indicated eating disorders by exercise addiction measurement type

\begin{tabular}{|c|c|c|c|c|c|c|}
\hline & & & Meta-analysis & Heterogeneity & Publication & \\
\hline $\begin{array}{l}\text { Exercise addiction } \\
\text { measurement tool }\end{array}$ & $\begin{array}{l}\text { Number of } \\
\text { studies }\end{array}$ & $\begin{array}{l}\text { Number of } \\
\text { subjects }\end{array}$ & $\begin{array}{l}\text { Odds ratio } \\
(95 \% \mathrm{CI})\end{array}$ & $\mathrm{I}^{2}$ & $\begin{array}{l}\text { Egger bias } \\
\text { and } \mathrm{P} \text {-value }\end{array}$ & $\begin{array}{l}\text { Trim-and-fill }(95 \% \mathrm{CI}) \\
\text { [number of studies trimmed] }\end{array}$ \\
\hline OEQ & 3 & 600 & $6.9(2.2-21.8)$ & 84.903 & $\begin{array}{l}-7.389 \\
p=0.219\end{array}$ & NA \\
\hline EDQ & 4 & 865 & $2.4(1.0-5.7)$ & 79.141 & $\begin{array}{l}-7.234 \\
p=0.296\end{array}$ & NA \\
\hline
\end{tabular}


